\title{
Safety and efficacy of a standardized intracameral combination of mydriatics and anesthetic for cataract surgery in type-2 diabetic patients
}

Marc Labetoulle ${ }^{1 *}$, Anders Behndig ${ }^{2}$, Marie-José Tassignon ${ }^{3}$, Rudy Nuijts ${ }^{4}$, Rita Mencucci ${ }^{5}$, José Luis Güell, $^{6}$ Uwe Pleyer $^{7}$, Jacek Szaflik ${ }^{8}$, Paul Rosen ${ }^{9}$, Alain Bérard ${ }^{10}$, Frédéric Chiambaretta ${ }^{11}$, Béatrice Cochener-Lamard ${ }^{12}$ and on behalf of the Intracameral Mydrane (ICMA), Ethics Group

\begin{abstract}
Background: Cataract surgery in diabetics is more technically challenging due to a number of factors including poor intraoperative pupil dilation and a higher risk of vision threatening complications. This study evaluates the safety and efficacy of an intracameral combination of 2 mydriatics and 1 anesthetic (ICMA, Mydrane) for cataract surgery in patients with well-controlled type-2 diabetes.

Methods: Post-hoc subgroup analysis of a phase 3 randomized study, comparing ICMA to a conventional topical regimen. Data were collected from 68 centers in Europe and Algeria. Only well-controlled type-2 diabetics, free of pre-proliferative retinopathy, were included. The results for non-diabetics are also reported. The primary efficacy variable was successful capsulorhexis without additional mydriatic treatment. Postoperative safety included adverse events, endothelial cell density and vision.
\end{abstract}

Results: Among 591 randomized patients, 57 (9.6\%) had controlled type 2 diabetes [24 (42.1\%) in the ICMA Group and 33 (57.9\%) in the Topical Group; intention-to-treat (ITT) set]. Among diabetics, capsulorhexis was successfully performed without additional mydriatics in 24 (96.0\%; modified-ITT set) patients in the ICMA Group and 26 (89.7\%) in the Topical Group. These proportions were similar in non-diabetics. No diabetic patient [1 (0.5\%) non-diabetics] in the ICMA Group had a significant decrease in pupil size $(\geq 3 \mathrm{~mm})$ intraoperatively compared to 4 (16.0\%; modifiedITT set) diabetics [16 (7.3\%) non-diabetics] in the Topical group. Ocular AE among diabetics occurred in 2 (8.0\%; Safety set) patients in the ICMA Group and 5 (16.7\%) in the Topical Group. Endothelial cell density at 1 month postoperatively was similar between groups in diabetics $(P=0.627)$ and non-diabetics $(P=0.368)$.

Conclusions: ICMA is effective and can be safely used in patients with well-controlled diabetes, with potential advantages compared to a topical regimen including reduced systemic risk, better corneal integrity and reduced risk of ocular complications.

Trial registration: The trial was registered at (reference \# NCT02101359) on April 2, 2014.

Keywords: Anesthetics, Cataract surgery, Diabetes, Intracameral, Mydrane, Mydriatics

\footnotetext{
* Correspondence: marc.labetoulle@bct.aphp.fr

'Service d'Ophtalmologie, Hôpital Bicêtre, APHP, Université Paris Sud, Le

Kremlin-Bicêtre, 94275 Paris, France

Full list of author information is available at the end of the article
}

(c) The Author(s). 2020 Open Access This article is distributed under the terms of the Creative Commons Attribution 4.0 International License (http://creativecommons.org/licenses/by/4.0/), which permits unrestricted use, distribution, and reproduction in any medium, provided you give appropriate credit to the original author(s) and the source, provide a link to the Creative Commons license, and indicate if changes were made. The Creative Commons Public Domain Dedication waiver (http://creativecommons.org/publicdomain/zero/1.0/) applies to the data made available in this article, unless otherwise stated. 


\section{Background}

The global prevalence of diabetes is estimated to reach 592 million by 2035 [1]. This figure represents a $64 \%$ increase in diabetics from 2013 levels, with a rate in the adult population of approximately 10\% in Europe and $9 \%$ in the USA [1-3]. The association of diabetes and cataracts is well documented, with a likelihood of developing cataract 2 to 5 times higher at a younger age, in patients with diabetes mellitus compared to non-diabetic patients [2-4]. Hence, the steady increase in the prevalence of diabetes in the general population will cause an increasing surgical burden of diabetic patients requiring cataract surgery [1]. Diabetics present a number of challenges for the cataract surgeon including miosis and poor pupillary dilation intraoperatively, epithelial and endothelial dysfunction and the potential for longer surgical times and higher risk of vision threatening complications such as posterior capsule rupture and macular oedema [4-6]. Hence, achieving a large, stable pupil in diabetics is optimal for mitigating these challenges.

Intracameral (IC) mydriatic delivery was developed to address some of the drawbacks of mydriatic eye drops and the safety and efficacy has been well documented [7-9]. Mydrane (Laboratoires Théa, Clermont-Ferrand, France) is a commercially available preservative-free ophthalmic combination of two mydriatics (tropicamide $0.02 \%$ and phenylephrine $0.31 \%$ ) and one anesthetic agent (lidocaine 1\%) for IC administration (ICMA), just prior to beginning cataract surgery [10]. A phase 3 clinical trial reported that ICMA is safe and effective for initiating and maintaining intraoperative mydriasis and analgesia in routine cataract surgery [10]. Additionally, pupil size after ICMA administration remained stable and was statistically larger at the end of surgery compared to a topical regimen [11]. If confirmed, these characteristics may be advantageous in the diabetic population to limit the risk of complications. Despite the association of diabetes and cataracts and challenges posed in cataract surgery, there are no studies on the efficacy and safety of ICMA in type 2 diabetics undergoing cataract surgery.

To investigate the performance of ICMA in diabetic patients, a post-hoc subgroup analysis of diabetics enrolled in the phase 3 study was performed. The current paper analyzes the efficacy and safety of ICMA in patients with well-controlled type 2 diabetes in comparison to non-diabetics.

\section{Methods}

The phase 3 study was a multicenter, international, randomized, parallel-group comparison of the safety and efficacy of ICMA (Mydrane) to a standard regimen of topical drops for cataract surgery [10]. The current paper presents a post-hoc subgroup analysis of the phase 3 study to assess the efficacy and safety of ICMA (ICMA
Group) versus standard preoperative eye drops regimen (Topical Group) in patients with stable type 2 diabetes. For general comparison, the results for non-diabetic patients are also reported. This study adhered to guidelines for Good Clinical Practice. Additionally, this study adhered to the tenets of the Declaration of Helsinki. Prior to enrolling patients, ethics committee approvals were received from each country. Before participating in the study, each patient was required to sign a written informed consent document. The local health regulations were followed in each country where patients were recruited. The trial was registered at http://clinicaltrials. gov (reference \# NCT02101359).

\section{Patients and inclusion criteria}

Inclusion criteria for the phase 3 study have been previously published [10]. Patients with poorly controlled or insulin-dependent diabetes were excluded. The most current medical records were assessed for signs of wellcontrolled diabetes including documented laboratory tests. Only patients with well-controlled type 2 diabetes mellitus were included in the study. Diabetic patients with signs of proliferative or pre-proliferative retinopathy (using slitlamp fundus examination), or signs of macular edema (retinal thickness using optical coherence tomography) were excluded. During the selection visit, preoperative pupil dilation of at least $7 \mathrm{~mm}$ had to be confirmed within $30 \mathrm{~min}$ of instilling a standard topical mydriatic regimen. Only one eye per patient was included in this study.

\section{Administration of Study Medications}

All investigators involved in this study had been selected on the basis of their experience (high volume cataract surgeries for several years) and their acceptance of being videorecorded for the purpose of masked analysis of the pupil size and other endpoints. Additionally, the randomization (ICMA vs. topical eye drops) was performed just before the surgery in order to keep the groups comparable (no possibility of changing the surgeon at the last moment), which was verified (comparable numbers of patients randomized in each group for a given investigator). Mydrane (Laboratoires Théa, Clermont-Ferrand, France) is a commercially available, injectable solution of $1 \%$ lidocaine combined with $0.31 \%$ phenylephrine and $0.02 \%$ tropicamide. Patients in the ICMA Group were injected with $200 \mu \mathrm{L}$ of ICMA in the anterior chamber just after the first corneal incision. In the Topical Group, the patients received 1 drop each of tropicamide $0.5 \%$ and phenylephrine $10 \%$, repeated 3 times at 10 min intervals beginning $30 \mathrm{~min}$ before surgery. Preoperatively, both groups received the same regimen of tetracaine $1 \%$ (1-2 drops at 5 and $1 \mathrm{~min}$ before surgery). Duovisc (Alcon Inc., Fort Worth, TX, USA) viscoelastic was used for all surgeries. 


\section{Measurements}

As previously described [10] all surgeries were videorecorded and pupil size measurements were performed by independent, trained personnel masked to the type of treatment (ICMA or topical regimen). Pupil size measurements were performed at 5 different intervals over the duration of surgery, as previously described [10]. Data were collected on the use of additional topical or intracameral medications preoperatively or intraoperatively for mydriasis or anesthesia. Postoperative visits were scheduled at 1 day, 1 week and 1 month postoperatively.

\section{Efficacy variables}

The ability to perform capsulorhexis without additional mydriatic treatment was the primary efficacy variable. A supplementary efficacy variable was the ability to perform capsulorhexis without using additional mydriatics and a pupil size at least $6.0 \mathrm{~mm}$ before capsulorhexis. Additional mydriatic treatments were pupillary expansion device and/or instillation of extra medication(s) for mydriasis (for example, extra drops of phenylephrine, cyclopentolate and/or tropicamide) that were not included in the clinical trial protocol, between the initial delivery of the intracameral or topical regimen and capsulorhexis. Other assessments included the change in pupil diameter and the number of patients with no sensation of ocular pain or pressure at the various stages of surgery. Data were collected on total surgical time and the time from capsulorhexis to the end of surgery. Each surgeon noted his/her subjective assessment of the different stages of surgery, using a published scale [10].

\section{Postoperative safety assessments}

Evaluation of postoperative safety included, measurement of best-corrected visual acuity (BCVA), ocular symptoms, slit lamp biomicroscopy and endothelial cell counts (ECC; at designated study sites based on availability of a specular microscope), funduscopy and systemic and ocular adverse events (AE). AEs were coded using the Medical Dictionary for Regulatory Activities (MedDRA) [12] (as defined in the clinical study protocol) and their severity graded using the following scale: mild - visible to the subject, but did not need any additional treatment and did not interfere with the subject's daily activities; moderate - troublesome, could require an additional treatment, but did not interfere with the subject's daily activities; severe - intolerable, could require an additional treatment or a modification of this treatment, could interfere with the subject's daily activities.

\section{Statistical analyses}

Data from the modified intention-to-treat (mITT) set were analyzed as previously described [10]. Analysis of safety included data from on all patients who received the study medications (Safety set). Data on anesthesia evaluation were included if the patient received no additional anesthetic prior to beginning surgery (mITT-An set). In the intention-to-treat (ITT) set, patients were excluded if they had treatment that could have affected mydriasis. Mainly descriptive statistics are reported. Between-group comparisons were performed with the Cochran-Mantel-Haenzel $(\mathrm{CMH})$ tests based on modified ridit scores and analysis of variance. $P<0.05$ indicates statistical significance.

\section{Results}

In the phase 3 study, 57 (9.6\%) patients with controlled type 2 diabetes mellitus were included among the 591 randomized patients. Among the diabetics, 24 (42.1\%) were randomized to receive ICMA and 33 (57.9\%) to receive the standard topical regimen (ITT set). The mITT set was comprised of 54 diabetics (ICMA group: 25 patients; Topical group: 29 patients), the mITT-An set of 50 (23 and 27, respectively) and the Safety set of 55 (25 and 30 , respectively). One patient randomized to the Topical Group (ITT) actually received ICMA and was included in the ICMA group for statistical analyses (mITT and Safety set). Table 1 presents the preoperative patient data for diabetics and non-diabetics (ITT set).

\section{Efficacy of Mydriasis}

Among diabetics, capsulorhexis was performed without additional mydriatic treatments in $96.0 \%$ (24/25 patients, mITT set) in the ICMA Group and $89.7 \%(26 / 29)$ in the Topical Group (Fig. 1a). Data were missing in some cases due to technical difficulties with the videorecorders or poor quality video that precluded measurement of pupil size. Capsulorhexis without the use of additional mydriatics and with a pupil size $\geq 6.0 \mathrm{~mm}$ was achieved in $91.7 \%$ (22/24 patients, mITT set, data missing for 1 patient) of diabetics in the ICMA Group versus $88.9 \%$ (24/27, data missing for 2 patients) in the Topical Group (Fig. 1b). These outcomes were similar among non-diabetics.

In the ICMA Group, the mean pupil size was unchanged in diabetics from just before capsulorhexis $(7.4 \pm 1.1 \mathrm{~mm}$; range: 5.0 to $10.1 \mathrm{~mm})$ to the end of surgery $(7.3 \pm 1.1 \mathrm{~mm}$; range: 5.2 to $9.6 \mathrm{~mm}$ ) (Fig. 2$)$. Although higher just prior to capsulorhexis in the Topical Group $(8.7 \pm 0.8 \mathrm{~mm}$; range: 6.7 to $10.1 \mathrm{~mm} ; P<0.001$ between groups), the pupil size decreased in this group to $6.8 \pm 1.3 \mathrm{~mm}$ (range: 4.8 to $9.7 \mathrm{~mm} ; P=0.109$ between groups) at the end of surgery. Non-diabetics in both groups showed similar trends.

\section{Stability of the pupil size}

The mean change in pupil diameter throughout surgery was smaller in diabetics and non-diabetics in the ICMA group (Fig. 3a). Among diabetics, the mean decrease in pupil size was $-0.11 \pm 0.72 \mathrm{~mm}$ (median: $0.03 \mathrm{~mm}$; range: 
Table 1 Preoperative characteristics of diabetics and non-diabetics who received intracameral ICMA or a topical regimen for cataract surgery (ITT set)

\begin{tabular}{|c|c|c|c|c|}
\hline & \multicolumn{2}{|l|}{ Diabetics } & \multicolumn{2}{|l|}{ Non-Diabetics } \\
\hline & ICMA Group $(N=24)$ & Topical Group $(N=33)$ & ICMA Group $(N=271)$ & Topical Group $(N=263)$ \\
\hline \multicolumn{5}{|l|}{ Gender } \\
\hline Male, n (\%) & $15(62.5)$ & $18(54.5)$ & $105(38.7)$ & $116(44.1)$ \\
\hline Female, n (\%) & $9(37.5)$ & $15(45.5)$ & $166(61.3)$ & $147(55.9)$ \\
\hline \multicolumn{5}{|l|}{ Age (years) } \\
\hline $\mathrm{n}$ & 24 & 31 & 251 & 255 \\
\hline Mean \pm SD & $70.4 \pm 9.2$ & $72.2 \pm 8.0$ & $69.1 \pm 9.5$ & $70.4 \pm 9.3$ \\
\hline Min - Max & $48-85$ & $52-84$ & $43-87$ & $34-88$ \\
\hline \multicolumn{5}{|c|}{ Time since cataract diagnosis (months) } \\
\hline$n$ & 24 & 31 & 252 & 255 \\
\hline Median & 4.2 & 2.8 & 4.3 & 4.2 \\
\hline Min - Max & $0.3-134.7$ & $0.2-57.5$ & $0.0-636.6$ & $0.0-111.9$ \\
\hline \multicolumn{5}{|c|}{ Visible iris diameter at selection (mm) } \\
\hline$n$ & 23 & 32 & 263 & 255 \\
\hline Mean \pm SD & $11.5 \pm 0.4$ & $11.8 \pm 0.5$ & $11.9 \pm 0.6$ & $11.9 \pm 0.5$ \\
\hline Min - Max & $10.9-12.5$ & $10.7-12.7$ & $10.0-14.0$ & $10.0-13.5$ \\
\hline
\end{tabular}

SD standard deviation, $n$ number of patients, Min minimum, Max maximum, ICMA Group = patients who received an intracameral injection of a standardized combination of $1 \%$ lidocaine, $0.02 \%$ tropicamide, and $0.31 \%$ phenylephrine immediately after the 1 st corneal incision; Topical Group $=$ patients who received a topical regimen of 1 drop each of $10 \%$ phenylephrine and $0.5 \%$ tropicamide

- 1.7 to $1.1 \mathrm{~mm}$ ) in the ICMA Group compared to $1.95 \pm 1.12 \mathrm{~mm}$ (median: $-1.94 \mathrm{~mm}$; range: -4.3 to -0.4 $\mathrm{mm}$ ) in the Topical Group from just before capsulorhexis to the end of surgery. The mean decrease in pupil size among non-diabetics was $-0.24 \pm 0.72 \mathrm{~mm}$ (range: -3.9 to $1.8 \mathrm{~mm}$ ) for the ICMA Group and $-1.63 \pm 0.96 \mathrm{~mm}$ (range: - 5.6 to $0.1 \mathrm{~mm}$ ) for the Topical Group. Over the same intraoperative period, no clinically significant change in pupil diameter (change less than $1 \mathrm{~mm}$ ) was noted in $82.6 \%$ (19/ 23 patients, mITT set, data missing for 2 patients) of diabetics $[90.0 \%(189 / 210$ patients) non-diabetics] in the
ICMA Group compared to $24.0 \%$ (6/25, data missing for 4 patients) of diabetics in the Topical Group [27.0\% (59/218) non-diabetics] (Fig. 3b). No diabetics [0.5\% (1/210 patients) non-diabetics] in the ICMA group had a significant decrease in pupil size $(\geq 3 \mathrm{~mm})$ intraoperatively compared to $16.0 \%(4 / 25)$ of diabetics [7.3\% (16/218) non-diabetics] in the Topical group.

\section{Efficacy of anesthetic}

The proportions of patients with no ocular pain/pressure for all phases of surgery was similar among diabetics and

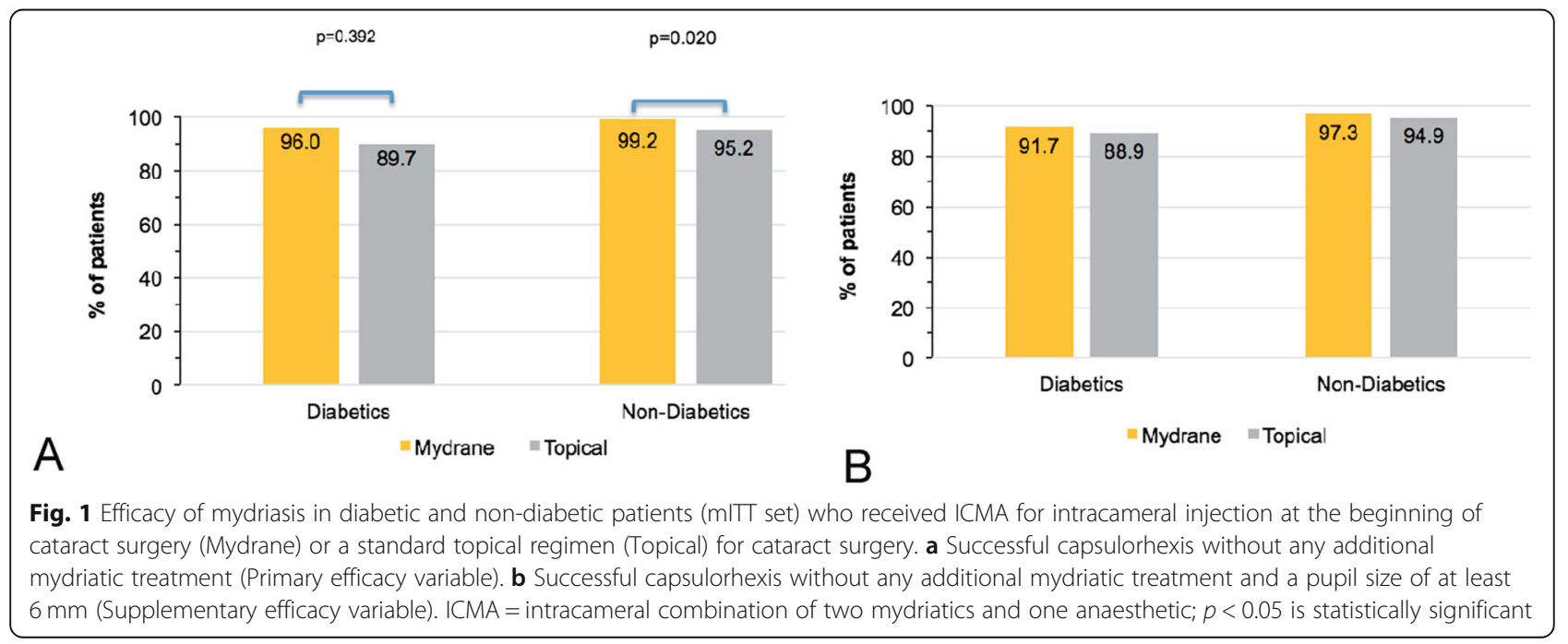




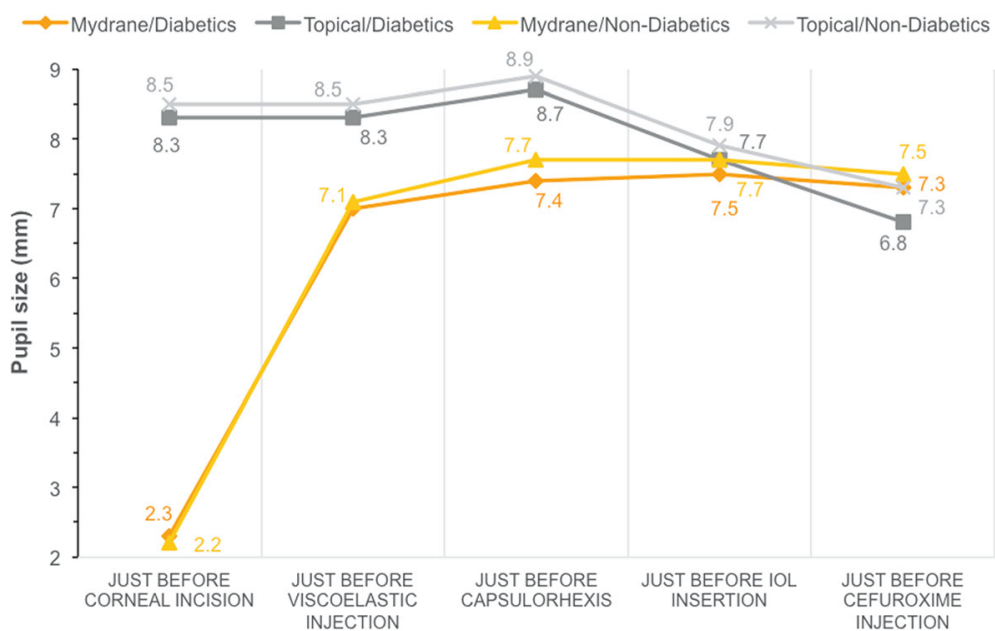

Fig. 2 Pupil size throughout cataract surgery among diabetics and non-diabetics ( $\mathrm{m} / \mathrm{TT}$ set) who received ICMA for intracameral injection at the beginning of cataract surgery (Mydrane) or a standard topical regimen (Topical) for cataract surgery. IOL = intraocular lens; ICMA =intracameral combination of two mydriatics and one anaesthetic

non-diabetics in the ICMA and Topical Groups $(P>$ 0.05 , all comparisons). Among diabetics, more patients in the ICMA Group $(69.6 \%, 16 / 23$ patients, mITT-An set) than the Topical Group (51.9\%, 14/27 patients, mITT-An set; $P=0.321$ ) reported no sensation of pain just before IOL insertion (ie, during the active phase of the surgery with the most surgical maneuvers). Nondiabetics had similar outcomes [78.8\% (160/203 patients) vs $69.9 \%(146 / 209)$, respectively; $P=0.067$.

\section{Duration of surgery}

The mean duration of the active phase of surgery (just prior to capsulorhexis to the end of surgery) was similar for diabetics [ICMA Group: 12.2 (range: 6.7 to 22.0) min; Topical Group: 12.8 (range: 6.8 to 27.8 ) $\mathrm{min} ; P=$
0.669 between groups] and non-diabetics [10.8 (range: 3.6 to 35.8 ) min vs 10.9 (range: 4.2 to 66.8 ) $\mathrm{min}$, respectively; $P=0.942$ ] (Fig. 4).

\section{Surgeon grading}

Surgeons graded the different phases of surgery as uncomplicated for most diabetic patients in both Groups [between $88.9 \%$ (48/54 patients, mITT set) and $92.6 \%$ (50/54)] ( $P>0.05$, all between-group comparisons). For non-diabetics, a statistically significantly lower number of slightly complicated or complicated cases during IOL implantation were reported in the ICMA Group compared to the Topical Group (2.9\%, 7/243 patients vs $7.1 \%, 18 / 252$ patients, respectively; $P=0.030$ ). There was no statistical between-group difference in surgeon

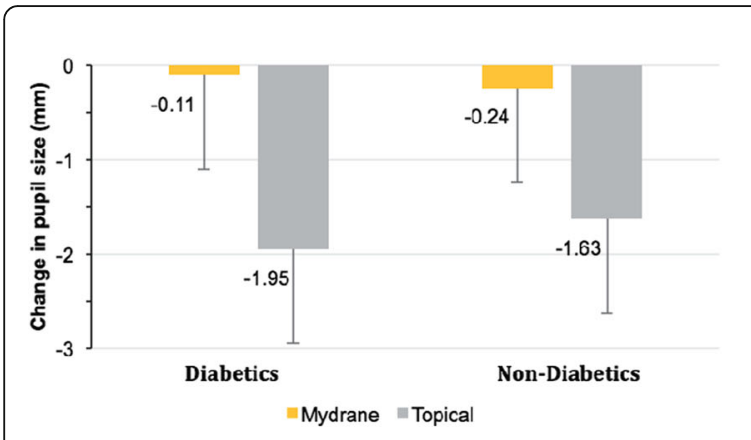

A

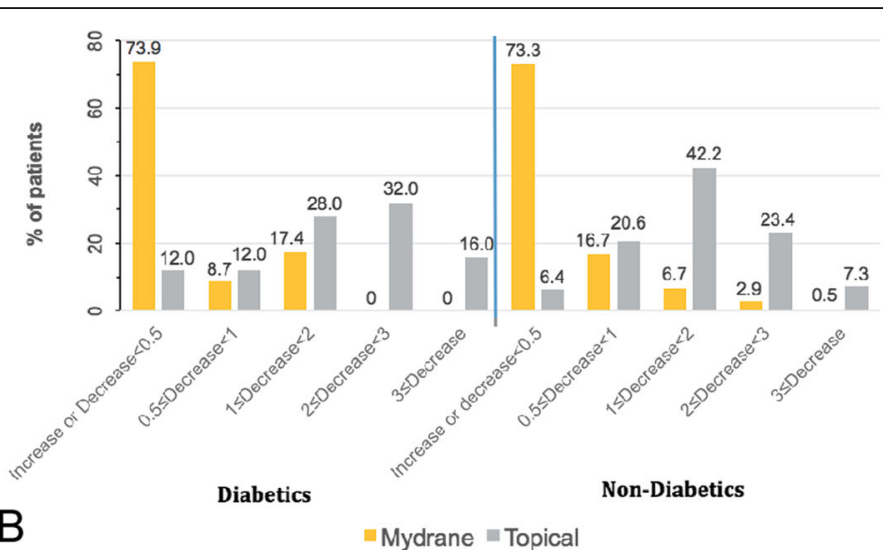

B

Mydrane $=$ Topical

Fig. 3 a Intraoperative change in pupil diameter starting just before capsulorhexis to the end of surgery among diabetic and non-diabetic patients ( $\mathrm{mlTT}$ set) who received ICMA for intracameral injection at the beginning of cataract surgery (Mydrane) or a standard topical regimen (Topical) for cataract surgery. b Stratification of change in pupil size from just before capsulorhexis to the end of surgery among diabetic and non-diabetic patients who received ICMA for intracameral injection at the beginning of cataract surgery or a standard topical regimen for cataract surgery. ICMA = intracameral combination of two mydriatics and one anaesthetic 


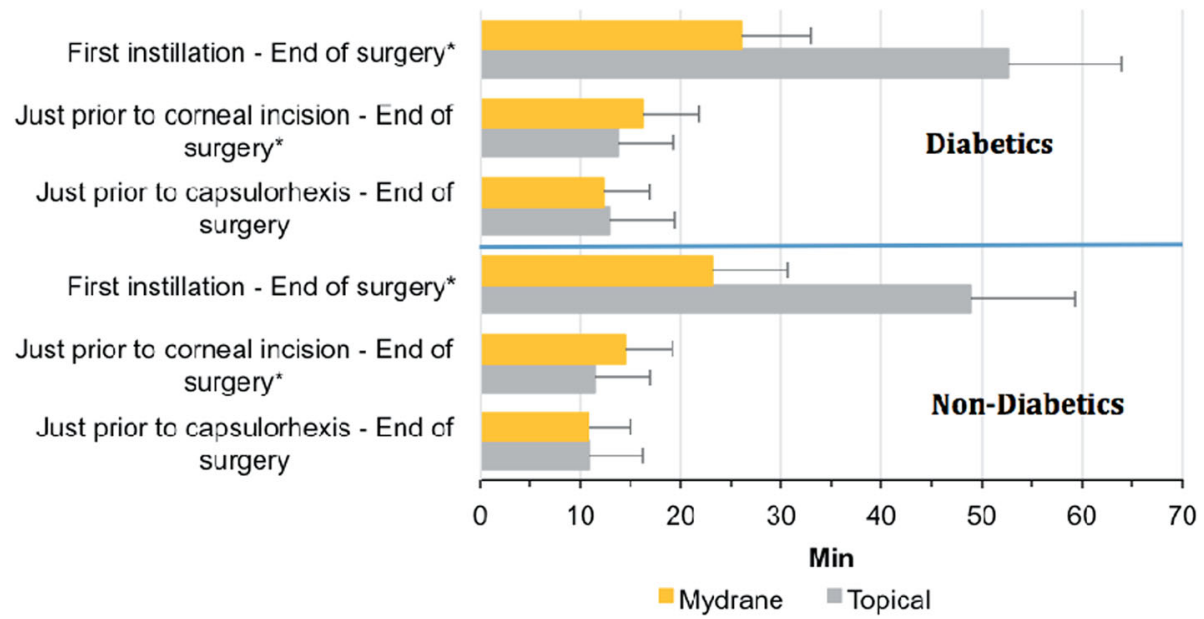

Fig. 4 Duration of the different phases of surgery for diabetic and non-diabetic patients (mITT set) who received ICMA for intracameral injection at the beginning of cataract surgery (Mydrane) or a standard topical regimen (Topical) for cataract surgery. These phases included a mandated 1 min 30 s waiting time for the ICMA Group in the study protocol. ICMA = intracameral combination of two mydriatics and one anaesthetic

grading among non-diabetic patients for the other phases of surgery $(P>0.05$, all comparisons).

\section{Safety}

The incidence of any ocular $\mathrm{AE}$ among diabetics was $8.0 \%(2 / 25$ patients, Safety set) in the ICMA Group and $16.7 \%$ (5/30 patients) in the Topical Group (Table 2).

Among diabetics, there were no ocular AE related to study treatment in both groups. The incidence of systemic $\mathrm{AE}$ was $4.0 \%$ (1/25 patients) in the ICMA Group and 3.3\% (1/30 patients) in the Topical Group. One serious systemic event (transient ischemic attack) was reported in the ICMA Group. None of the systemic AEs were related to the study medication.

Table 2 Adverse events in diabetics who received intracameral ICMA or a topical regimen for cataract surgery (Safety set)

\begin{tabular}{ll}
\hline ICMA Group & Topical Group \\
\hline $\begin{array}{l}\text { Complications (number of } \\
\text { patients) }\end{array}$ & Complications (number of patients) \\
Mild conjunctival hyperaemia (1) & Mild conjunctivitis (1) \\
Mild punctate keratitis (1) & Moderate punctate keratitis (2) \\
& Moderate dry eye (1) \\
& Moderate eyelid ptosis (1) \\
& Moderate posterior capsule rupture \\
& $(1)^{a}$ \\
Severe transient ischaemic attack & Mild type 2 diabetes mellitus (1) \\
$(1)$ & \\
\hline
\end{tabular}

ICMA Group = patients who received an intracameral injection of a standardized combination of $1 \%$ lidocaine, $0.02 \%$ tropicamide, and $0.31 \%$ phenylephrine immediately after the 1 st corneal incision

Topical Group $=$ patients who received a topical regimen of 1 drop each of

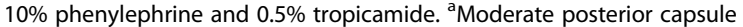
rupture was a limited rupture that did not require anterior vitrectomy
There was no statistical between-group difference in the endothelial cell density at 1 month postoperatively among diabetics $(P=0.627)$ and non-diabetics $(P=$ 0.368) (Table 3).

Seven diabetics who received 2 (or more) injections of ICMA had a higher change in endothelial cell density of $375.4 \pm 349.5$ (range: -955 to 31 ) cells $/ \mathrm{mm}^{2}$ (-15.8\%) than patients who were injected only once. For the 39 non-diabetic patients who received 2 (or more) injections of ICMA, the change in endothelial cell density was $318.4 \pm 479.1$ (range: -1843 to 324 ) cells $/ \mathrm{mm}^{2}$ (-10.7\%).

At 1 week postoperatively, none of the diabetics reported ocular pain. Among non-diabetics, ocular pain was reported at 1 week postoperatively by statistically significantly fewer patients in the ICMA Group $(0.8 \%, 2$ / 246 patients, Safety set) compared to the Topical Group (4.4\%, $11 / 249$ patients; $P=0.004$ ). Irritation/burning/ stinging of the eye at 1 month postoperatively was reported by $8.0 \%(2 / 25)$ of patients in the ICMA Group and $17.2 \%(5 / 29)$ in the Topical Group among diabetics $(P=0.296)$, and by statistically significantly fewer patients in the ICMA Group (4.6\%, 11/241 patients) compared to the Topical Group (11.7\%, 29/248 patients) among non-diabetics $(P=0.008)$.

Postoperatively, there were no clinically significant concerns in diabetics from the ICMA and Topical groups in terms of ocular inflammation (based on assessing anterior chamber cells/flare), corneal pachymetry, retinal thickness, retinal examination and intraocular pressure. All diabetics but one benefited from cataract surgery, with visual acuity increasing by at least 3 lines in 83.3\% (20/24 patients, Safety set, data missing for 1 patient) of diabetics in the ICMA Group and 90.0\% (27/30 patients) in the Topical Group at last visit. 
Table 3 Change in endothelial cell density from preoperatively to 1 month postoperatively (Safety set)

\begin{tabular}{|c|c|c|c|c|}
\hline & \multicolumn{2}{|l|}{ Diabetics } & \multicolumn{2}{|l|}{ Non-Diabetics } \\
\hline & ICMA Group $(N=16)$ & Topical Group $(N=12)$ & ICMA Group $(N=150)$ & Topical Group $(N=156)$ \\
\hline \multicolumn{5}{|c|}{ Preoperative Endothelial Cell Density (cells $/ \mathrm{mm}^{2}$ ) } \\
\hline Mean \pm SD & $2262.1 \pm 396.3$ & $2345.9 \pm 283.5$ & $2400.1+420.6$ & $2401.9 \pm 415.3$ \\
\hline Min - Max & $1330-2813$ & $1970-2943$ & 1498-3692 & $974-3662$ \\
\hline \multicolumn{5}{|c|}{ Change in Endothelial Cell Density at 1 month post-surgery (cells/mm²) } \\
\hline Mean \pm SD & $-163.4 \pm 347.5$ & $-121.3 \pm 412.0$ & $-224.8 \pm 417.3$ & $-185.2 \pm 388.6$ \\
\hline (\%) & $(-7.2)$ & $(-5.2)$ & $(-9.4)$ & $(-7.7)$ \\
\hline Min - Max & $-955-526$ & $-749-708$ & $-1843-976$ & $-2076-600$ \\
\hline
\end{tabular}

A decrease in endothelial cell counts is indicated by negative numbers; ICMA Group = patients who received an intracameral injection of a standardized combination of $1 \%$ lidocaine, $0.02 \%$ tropicamide, and $0.31 \%$ phenylephrine immediately after the 1 st corneal incision. Topical Group $=$ patients who received a topical regimen of 1 drop each of $10 \%$ phenylephrine and $0.5 \%$ tropicamide

\section{Discussion}

Cataract surgery in diabetics can be challenging due to the poor pupillary response to mydriatics [13-16]. Currently, in Western countries, 1 in 5 patients undergoing cataract surgery is diabetic [17]. The outcomes of this study indicate that ICMA was equivalent to a standard topical regimen for cataract surgery in diabetics and the efficacy of ICMA was equivalent to the use of ICMA (and topical regimen) in non-diabetic patients. ICMA injection just after the first corneal incision resulted in rapid and stable mydriasis without requiring additional mydriatics or pupil expanders in the large majority of diabetics, similar to the standard topical regimen and to non-diabetics.

A 6-mm pupil is commonly considered adequate for performing capsulorhexis $[6,11,18-20]$. In the phase 3 study, surgeons felt the pupil size after ICMA was adequate for safely performing cataract surgery [10]. Given the similar outcomes in the current study, ICMA should also be adequate for cataract surgery in patients with well-controlled diabetes.

Stable mydriasis is fundamental for cataract surgery [18]. We found that the change in intraoperative pupil size in diabetics in the ICMA Group was smaller than in the Topical Group of diabetics. Additionally, the large majority of diabetics (73.9\%) in the ICMA Group experienced a decrease less than $0.5 \mathrm{~mm}$ in pupil size from capsulorhexis to the end of surgery. These outcomes for diabetics are comparable to previous comparisons of ICMA and topical regimen in non-diabetics $[10,11]$.

Intraoperative miosis with topical therapy is well documented $[6,10,20]$. This factor becomes especially important in diabetics who may have an abnormal iris response to mydriatics due to autonomic dysfunction [6], a larger [21] or more tenacious lens [16] and anterior chamber shallowing [22], which may predispose to a more technically demanding surgery. Intracameral delivery of ICMA may mitigate the risk of complications such as posterior capsular rupture in diabetics due to stable mydriasis and a pupil size that remains $7 \mathrm{~mm}$ or larger to the end of surgery as reported in both diabetics and non-diabetics in the ICMA Group in the current analysis. An additional advantage of using ICMA for diabetics is the reduced quantity of injected mydriatics, limiting their systemic absorption in a population with higher cardiovascular risks [10, 14].

Pain during the surgical maneuvers of cataract surgery may lead to an uncooperative patient. The presence of lidocaine in ICMA may mitigate intraocular pain during cataract surgery $[23,24]$. Additionally, the use of ICMA may decrease the number of topical drops used compared to topical regimens, thus mitigating ocular surface toxicity. This is of particular interest as diabetic keratopathy is one of the numerous ocular complications associated with diabetes. The compromised integrity of the corneal epithelium and ocular surface may make diabetics more prone to corneal damage $[6,13]$. Topical mydriatics and anesthetics can disrupt the corneal epithelium making the diabetic cornea more susceptible to punctate keratitis and infections [6, 13]. Impaired corneal wound healing among diabetics would further increase the risk of trophic complications [6, 13]. By reducing the mydriatic and anesthetic load on the cornea and delivering these agents to the intended site of action, ICMA may reduce the risk of postoperative corneal complications.

Longer procedures may also lead to an uncooperative patient during surgery. Based on previous experience [25], ICMA may decrease the duration of the entire procedure (preoperative care, perioperative and discharge) in actual clinical practice because it dispenses with the requirements of repeated instillation of medications well before the beginning of the procedure.

Surgeons graded surgery as mostly uncomplicated in both diabetic groups. In the current study, there were no safety concerns regarding the use of ICMA in diabetics. For example, there were no ocular or systemic events related to the study medications. The ocular AEs that 
occurred in the two diabetics in the ICMA Group were mild and resolved with observation without further sequelae. One serious case of transient ischemic attack occurred in one diabetic patient in the ICMA Group that was deemed by the investigator as unrelated to the study medication (occurred 6 days postoperatively and was more likely due to a history of vascular disorders, including high blood pressure and a stroke 4 years previously). Endothelial cell loss was similar in diabetics and nondiabetics. This loss was well within the range (9 to $11 \%$ ) reported for non-diabetics undergoing cataract surgery with the standard topical regimen for anesthesia and mydrasis $[26,27]$. However, the small sample of patients that underwent endothelial microscopy warrants judicious interpretation of this outcome. Endothelial cell loss was greater in patients who received 2 or more injections of ICMA in both diabetics and non-diabetics. During the phase 3 study, surgeons were allowed to deliver more than one injection of ICMA if they deemed the pupil size was inadequate. A lack of experience with ICMA and the early learning curve for ICMA was the most common reason for the delivery of the additional doses. Masked analysis of the surgical videos indicated that the extra injections offered no clinically significant value. Subsequent approval and the product monograph states that only one injection of ICMA is recommended as greater dilation is not achieved with additional doses [11]. At last visit postoperatively, there were no clinically significant concerns related to ICMA in diabetics.

This study has some limitations. The small sample size, the post-hoc analysis and the absence of stratification from the inception of the study for diabetics resulted in insufficient power to determine subtle differences between diabetics in the ICMA and Topical Groups. However, the randomized nature of the overall study mitigated bias in the outcomes. Additionally, we found no clinically significant differences in using ICMA in diabetic compared to non-diabetic patients. Surgeon experience was likely not a factor in the outcomes as the same surgeons performed surgery in diabetics and non-diabetic patients, hence surgeon seniority, experience and skill should affect both groups equally.

\section{Conclusions}

Analysis of the diabetic subpopulation in this phase 3 study indicates that intracameral administration of ICMA just after the first corneal incision is an effective and safe alternative to the routine topical regimen for initiating and maintaining intraoperative mydriasis during cataract surgery in diabetic patients. Additionally, the anterior chamber structures in a diabetic eye (without significant diabetic retinopathy) seem to respond similarly to the normal non-diabetic anterior chamber structures after injection of ICMA. Administration of
ICMA should only be performed in patients (including diabetics) who have previously demonstrated satisfactory pupil dilation with topical mydriatics. It can be safely used in patients with controlled diabetes, with potential advantages compared to the conventional eye drop regimen regarding reduced systemic risk, better corneal integrity and reduced risk of ocular complications.

\section{Abbreviations}

AE: Adverse event; BCVA: Best-corrected visual acuity; CMH: Cochran-MantelHaenzel; ECC: Endothelial cell count; IC: Intracameral; ICMA: Intracameral combination of 2 mydriatics and 1 anesthetic; ITT: Intention-to-treat; mITT: Modified intention-to-treat; mITT-An: Modified intention-to-treat anesthesia set

\section{Acknowledgements}

Members of the Intracameral Mydrane (ICMA) and Ethics Group.

C. Aguiar, Hospital de Santo Antonio, Porto, Portugal

J. Alio, Instituto Oftalmologico de Alicante, Alicante, Spain

S. Allieu, Clinique Beau Soleil, Montpellier, France

A. Behndig, Umeå University Hospital, Umeå, Sweden

G. Beltram, U.O. di Oculistica, Azienda Ospedaliera, Pordenone, Italy

S. E. Benmoussa, Clinique d'Ophtalmologie Benmoussa, Constantine, Algeria

A. Berard, Hôpital privé Les Franciscaines, Nîmes, France

P. Bonicel, Centre Hospitalier Régional, Orléans, France

J.M. Bosc, Clinique Sourdille, Nantes, France

P. Bouchut, Clinique Ophtalmologique Thiers, Bordeaux, France

T. Bourcier, Nouvel Hôpital Civil, Strasbourg, France

C. Boureau-Andrieux, Clinique Geoffroy Saint-Hilaire, Paris, France

J.-M. Buffet, Polyclinique Saint-François, Desertine, France

F. Chiambaretta, Hôpital Gabriel Montpied, CHU de Clermont-Ferrand,

Clermont-Ferrand, France

B. Cochener, CHU Morvan, Brest, France

I. Cochereau, Fondation A. de Rothschild, Paris, France

J. Colin, Hôpital Pellegrin Tripode, Bordeaux, France

J. Costa Vila, Clínicas Corachán, Barcelona, Spain

M. Daghbouche, Clinique Ophtalmologique Daghbouche, Constantine,

Algeria

B. Delemazure, Centre Hospitalier de Belfort-Montbéliard, Belfort, France N. Duquesne, Clinique Saint Charles, Lyon, France

F. Fasce, U.O. C. di Oculistica, Fondazione Centro S. Raffaele, Milano, Italy

J. Fernandez, Hospital Torrecárdenas, Almeria, Spain

O. Findl, Hanush Krankenhaus Wien, Wien, Austria

N. Francoz, Polyclinique La Pergola, Vichy, France

P. Gain, Centre Hospitalier Bellevue, CHU Saint Etienne, Saint Etienne, France

P. Gohier, CHRU Hôtel Dieu, Angers, France

G. Grabner, Universitätsklinik Für Augenheilkunde Und Optometrie, Der

Paracelsus, Austria

J. L. Güell - Instituto Microcirugía Ocular (IMO), Barcelona, Spain

D. Hartani, CHU Mustapha, Alger, Algeria

S. Jaulerry, Centre Hospitalier de Bigorre, Tarbes, France

A. Kampik, AugenKlinik der Ludwig-Maximilians, Universität München, Munich, Germany

M. Labetoulle, Hôpital Bicêtre, Université Paris Sud, Paris, France

I. Lanzl, Chiemsee Augen Tagesklinik, Prien, Germany

L. Laroche, CHNO des XV-XX, Paris, France

C. G. Laurell, St. Erik Eye Hospital, Stockholm, Sweden

S. Lazreg, Centre d’Ophtalmologie Lazreg, Blida, Algeria

B. Le Bot, Clinique de la côte d'Emeraude, Saint Malo, France

T. Lebrun, Clinique du Landy, Saint-Ouen, France

P. Lenoble, Hôpital Emile Muller, Centre Hospitalier de Mulhouse, Mulhouse, France

F. L'Herron, Clinique Saint-Michel et Sainte-Anne, Quimper, France A. Liekfeld, Ernst von Bergman Klinikum, Potsdam, Germany

A. Limao, Instituto de Microcirugia Ocular (IMO), Lisboa, Portugal

M. Lobo, Association for Innovation and Biomedical Research on Light and Image (AIBILI), Centro Hospitalar e Universitário de Coimbra, Coimbra, Portugal

F. Malacaze, Hôpital Purpan, CHU de Toulouse, Toulouse, France 
C. Mazit, Clinique de l'Anjou, Angers, France

U. Menchini, A.O.U. Careggi, Clinica Oculistica, Firenze, Italy

R. Mencucci, A.O.U. Careggi, Clinica Oculistica, Università degli Studi di Firenze, Firenze, Italy

M. Mercie, Hôpital Jean Bernard, Poitiers, France

E. Mertens, Medipolis, Antwerpen, Belgium

M. Meziane, Clinique d'Ophtalmologie Nour, Oran, Algeria

D. Milea, CHRU Hôtel Dieu, Angers, France

S. Mohabeddine, Clinique Diar Saada, Alger, Algeria

M. Muraine, Hôpital Charles Nicolle, CHU de Rouen, Rouen, France

A. Muselier, Hôpital Général, CHU de Dijon, Dijon, France

F. Normand, Centre Hospitalier Saint Joseph Saint Luc, Lyon, France

R. Nuijts, University Eye Clinic, Maastricht University Medical Centre,

Maastricht, the Netherlands

J.-M. Perone, CHR Bon Secours, Metz, France

C. Pey, Clinique Bon Secours, Le Puy en Velay, France

P.-J. Pisella, Hôpital Bretonneau, CHRU de Tours, Tours, France

U. Pleyer, Universitäts-Augenklinik, Charité Campus Virchow-Klinik, Berlin, Germany

S. Pourjavan, Cliniques Universitaires Saint-Luc, Bruxelles, Belgium

P.-Y. Robert, Hôpital Dupuytren, CHU de Limoges, Limoges, France

P. Rosen, Oxford Eye Hospital, Oxford, United Kingdom

P. Rozot, Clinique Monticelli, Marseille, France

N. Salaun, Hôpital d'Instruction des Armées Legouest, Metz, France

G. Sallet, Ooginstituut, Aalst, Belgium

A. Smaili, Clinique d'Ophtalmologie En-Nour, Batna, Algeria

J. Szaflik, Department of Ophthalmology, Medical University of Warsaw, Warszawa, Poland

M.-J. Tassignon, Universitair Ziekenhuis Antwerpen, Edegem, Belgium

J. Torras, Hospital Casa De Maternitat, Barcelona, Spain

J. M. Trigo, Centro Hospitalar de Lisboa Central, Hospital de Santo Antonio

dos Capuchos, Lisboa, Portugal

J. Uzzan, Clinique Mathilde, Rouen, France

M. Weber, Clinique Ophtalmologique, Nantes, France

W. Williamson, Centre Hospitalier F. Mitterand, Pau, France

\section{Authors' contributions}

$M L, A B 1$, JS, PR, MJT, RN, BCL, FC, UP contributed to the conception and design of the study; RM, JLG, FC, ML, AB1, AB2, MJT, BCL, UP were responsible for the acquisition of data and analysis; JS, RN, PR, FC, ML, BCL, $A B 1, U P, A B 2$ interpreted the data; $J S, P R, M L, R N, A B 1, B C L$, $A B 2$ drafted the work or substantively revised it. All authors read and approved the final manuscript.

\section{Funding}

This research received no specific grant from any funding agency in the public, commercial, or not-for-profit sectors. The original phase 3 study was sponsored by Laboratories Thea. The Sponsor participated in supervision by the scientific committee in the design of the study, and provided support for the study conduct, data collection, management and statistical analyses.

\section{Availability of data and materials}

Data available on request Marc Labetoulle MD, PhD. Service d'Ophtalmologie, Hôpital Bicêtre, APHP, Université Paris Sud. 94275 Le Kremlin-Bicêtre, France. E-mail: marc.labetoulle@bct.aphp.fr; Phone: 33145 213690.

\section{Ethics approval and consent to participate}

Written informed consent was obtained from each patient. Ethics committee approvals were obtained in each country prior to enrolling any patient from each of the following committees:

1. COMITE DE PROTECTION DES PERSONNES SUD-OUEST ET OUTRE-MER III for all the study centres in France: Hôpital Bicêtre, Hôpital privé Les Franciscaines, Hôpital Gabriel Montpied and CHU Morvan.

2. REGIONALA ETIKPRÖVNINGSNÄMNDEN I UMEÅ for Umeå University Hospital, Umeå, Sweden.

3. COMITE VOOR MEDISCHE ETHIEK for Universitair Ziekenhuis Antwerpen, Edegem, Belgium.

4. University Eye Clinic, Maastricht University Medical Centre, Maastricht, the Netherlands.
5. COMITATO ETICO DELL'AZIENDA OSPEDALIERO-UNIVERSITARIA for A.O.U. Careggi for Clinica Oculistica, Università degli Studi di Firenze, Firenze, Italy. 6. COMITÉ ÉTICO DE INVESTIGACIÓN CLÍNICA DEL HOSPITAL CLÍNIC I PROVINCIAL DE BARCELONA for Instituto Microcirugía Ocular (IMO),

Barcelona, Spain.

7. ETHIKKOMMISSION BEI DER LMU MÜNCHEN for Universitäts-Augenklinik, Charité Campus Virchow-Klinik, Berlin, Germany.

\section{Consent for publication}

Not applicable.

\section{Competing interests}

Dr. Labetoulle reports personal fees from ALCON, personal fees from Allergan, personal fees from Bausch \& Lomb, personal fees from Dompe, personal fees from Horus, personal fees from MSD, personal fees from Novartis, personal fees from Santen, personal fees from Shire, grants and personal fees from Laboratoires Thea, outside the submitted work. Dr. Behndig has nothing to report. Dr. Tassignon reports personal fees from Laboratoires Thea, personal fees from Zeiss, personal fees from Morcher, personal fees from Ziemer, outside the submitted work. Dr. Nuijts reports grants, personal fees and non-financial support from Laboratoires Thea, during the conduct of the study; grants from Alcon, grants from Abbott AMO, grants from Bausch and Lomb, outside the submitted work. Dr. Mencucci has nothing to disclose. Dr. Pleyer has nothing to disclose. Dr. Güell is a Consultant for Ophtec, Kowa Zeiss Meditec, Alcon, Laboratoires Thea, Orca Surgical and an owner of Calhoun Vision and Visiometrics and received a grant from instituto Microcirugia Ocular. Dr. Szaflik has nothing to disclose. Dr. Rosen has nothing to disclose. Dr. Bérard has received funding for participating in the study from Laboratoires Thea. Dr. Chiambaretta was a consultant for Laboratoires Thea, Novartis and Santen. Dr. Cochener-Lamard reports grants from Alcon, personal fees from Zeiss, personal fees from Johnson and Johnson, personal fees from Hoya, grants and personal fees from Laboratoires Thea, personal fees from Santen, personal fees from Cutting Edge, and personal fees from Horus, outside the submitted work.

\section{Author details}

${ }^{1}$ Service d'Ophtalmologie, Hôpital Bicêtre, APHP, Université Paris Sud, Le Kremlin-Bicêtre, 94275 Paris, France. ${ }^{2} U$ meå University Hospital, Umeå, Sweden. ${ }^{3}$ Universitair Ziekenhuis Antwerpen, Edegem, Belgium. ${ }^{4}$ University Eye Clinic, Maastricht University Medical Centre, Maastricht, the Netherlands. ${ }^{5}$ A.O.U. Careggi, Clinica Oculistica, Università degli Studi di Firenze, Florence, Italy. ${ }^{6}$ Instituto Microcirugía Ocular (IMO), Barcelona, Spain.

7 Universitäts-Augenklinik, Charité Campus Virchow-Klinik, Berlin, Germany. ${ }^{8}$ Department of Ophthalmology, Medical University of Warsaw, Warszawa, Poland. ${ }^{9}$ Oxford Eye Hospital, Oxford, UK. ${ }^{10}$ Hôpital privé Les Franciscaines, Nîmes, France. ${ }^{11}$ Hôpital Gabriel Montpied, CHU de Clermont-Ferrand, Clermont-Ferrand, France. ${ }^{12} \mathrm{CHU}$ Morvan, Brest, France.

Received: 4 December 2019 Accepted: 14 February 2020 Published online: 03 March 2020

\section{References}

1. Guariguata L, Whiting DR, Hambleton I, Beagley J, Linnenkamp U, Shaw JE. Global estimates of diabetes prevalence for 2013 and projections for 2035. Diabetes Res Clin Pract. 2014;103:137-49.

2. Becker C, Schneider C, Aballéa S, Bailey C, Bourne R, Jick S, et al. Cataract in patients with diabetes mellitus-incidence rates in the UK and risk factors. Eye (Lond). 2018:32:1028-35.

3. Srinivasan S, Raman R, Swaminathan G, Ganesan S, Kulothungan V, Sharma T. Incidence, progression, and risk factors for cataract in type 2 diabetes. Invest Ophthalmol Vis Sci. 2017;58:5921-9.

4. Javadi MA, Zarei-Ghanavati S. Cataracts in diabetic patients: a review article. J Ophthalmic Vis Res. 2008;3:52-65.

5. Srinivasan S. Cataract surgery in patients with diabetes. J Cataract Refract Surg. 2017:43:1369-70

6. Joshi RS. Phacoemulsification without preoperative mydriasis in patients with age-related cataract associated with type 2 diabetes. Clin Ophthalmol. 2016;10:2427-32.

7. Lundberg B, Behndig A. Intracameral mydriatics in phacoemulsification cataract surgery -- a 6-year follow-up. Acta Ophthalmol. 2013;91:243-6. 
8. Lundqvist O, Behndig A. Posterior chamber injection of intracameral mydriatics increases the durability of the mydriatic response. Acta Ophthalmol. 2013;91:657-9.

9. Mori $Y$, Miyai T, Kagaya F, et al. Intraoperative mydriasis by intracameral injection of mydriatic eye drops: in vivo efficacy and in vitro safety studies. Clin Exp Ophthalmol. 2011;39:456-61.

10. Labetoulle M, Findl O, Malecaze F, Alió J, Cochener B, Lobo C, Lazreg S, Hartani D, Colin J, Tassignon MJ, Behndig A; Intracameral Mydrane Study 2 Group. Evaluation of the efficacy and safety of a standardised intracameral combination of mydriatics and anaesthetics for cataract surgery. $\mathrm{Br} J$ Ophthalmol. 2016;100:976-85.

11. Chiambaretta F, Pleyer U, Behndig A, Pisella PJ, Mertens E, Limao A, Fasce F, Fernandez J, Benmoussa SE, Labetoulle M, Cochener B, Intracameral Mydrane (ICMA) and Ethics Group. Pupil dilation dynamics with an intracameral fixed combination of mydriatics and anesthetic during cataract surgery. J Cataract Refract Surg. 2018;44:341-7.

12. Brajovic S, Blaser DA, Zisk M, Caligtan C, Okun S, Hall M, Pamer CA. Validating a framework for coding patient-reported health information to the medical dictionary for regulatory activities terminology: an evaluative study. JMIR Med Inform. 2018;6:e42.

13. Ljubimov AV. Diabetic complications in the cornea. Vis Res. 2017;139:138-52.

14. Fraunfelder FT, Scafidi AF. Possible adverse effects from topical ocular $10 \%$ phenylephrine. Am J Ophthalmol. 1978;85:447-53.

15. Karavanaki K, Davies AG, Hunt LP, Morgan MH, Baum JD. Pupil size in diabetes. Arch Dis Child. 1994;71:511-5.

16. Yanoff M, Fine BS, Berkow JW. Diabetic lacy vacuolation of iris pigment epithelium; a histopathologic report. Am J Ophthalmol. 1970;69:201-10.

17. Hamilton AMP, Ulbig MW, Polkinghorne P. Management of Diabetic Retinopathy. London: BMJ Publishing Group; 1996. p. 1-15.

18. Conrad-Hengerer I, Hengerer FH, Schultz T, Dick HB. Femtosecond laserassisted cataract surgery in eyes with a small pupil. J Cataract Refract Surg. 2013;39:1314-20.

19. Behndig A, Cochener-Lamard B, Güell J, Kodjikian L, Mencucci R, Nuijts R, Pleyer U, Rosen P, Szaflik J, Tassignon MJ. Surgical, antiseptic, and antibiotic practice in cataract surgery: results from the European observatory in 2013. J Cataract Refract Surg. 2015;41:2635-43.

20. Lundberg B, Behndig A. Intracameral mydriatics in phacoemulsification cataract surgery. I Cataract Refract Surg. 2003;29:2366-71.

21. Brown N, Hungerford J. The influence of the size of the lens in ocular disease. Trans Ophthalmol Soc UK. 1982;102(Pt 3):359-63.

22. Sparrow JM, Bron AJ, Brown NA, Neil HA. Biometry of the crystalline lens in early-onset diabetes. Br J Ophthalmol. 1990;74:654-60.

23. Ezra DG, Nambiar A, Allan BD. Supplementary intracameral lidocaine for phacoemulsification under topical anesthesia. A meta-analysis of randomized controlled trials. Ophthalmology. 2008;115:455-87.

24. Tan CS, Fam HB, Heng WJ, et al. Analgesic effect of supplemental intracameral lidocaine during phacoemulsification under topical anesthesia: a randomized controlled trial. Br J Ophthalmol. 2011:95:837-41.

25. Davey K, Chang B, Purslow C, Clay E, Vataire AL. Budget impact model of Mydrane ${ }^{\oplus}$, a new intracameral injectable used for intra-operative mydriasis, from a UK hospital perspective. BMC Ophthalmol. 2018;18:104

26. Hugod M, Storr-Paulsen A, Norregaard JC, Nicolini J, Larsen AB, Thulesen J. Corneal endothelial cell changes associated with cataract surgery in patients with type 2 diabetes mellitus. Cornea. 2011;30:749-53.

27. He X, Diakonis VF, Alavi Y, Yesilirmak N, Waren D, Donaldson K. Endothelial cell loss in diabetic and nondiabetic eyes after cataract surgery. Cornea. 2017;36:948-51.

\section{Publisher's Note}

Springer Nature remains neutral with regard to jurisdictional claims in published maps and institutional affiliations.

Ready to submit your research? Choose BMC and benefit from:

- fast, convenient online submission

- thorough peer review by experienced researchers in your field

- rapid publication on acceptance

- support for research data, including large and complex data types

- gold Open Access which fosters wider collaboration and increased citations

- maximum visibility for your research: over $100 \mathrm{M}$ website views per year

At BMC, research is always in progress.

Learn more biomedcentral.com/submissions 